\title{
The Effect of Emotional Intelligence and Academic Social Networking Sites on Academic Performance During the COVID-I9 Pandemic
}

\author{
Javed lqbal (i) 1,2,* \\ Naima Qureshi \\ Muhammad Azeem Ashraf (iD ${ }^{3, *}$ \\ Samma Faiz Rasool iD ${ }^{4}$ \\ Muhammad Zaheer Asghar (iD ${ }^{5}$ \\ 'School of Education, Guangzhou \\ University, Guangzhou, People's Republic \\ of China; ${ }^{2}$ Division of Education, \\ University of Education, Lahore, Pakistan; \\ ${ }^{3}$ Research Institute of Education Science, \\ Hunan University, Changsha, Hunan, \\ People's Republic of China; ${ }^{4}$ School of \\ Innovation and Entrepreneurship, \\ Entrepreneurship Institute, Guangzhou \\ University, Guangzhou, People's Republic \\ of China; ${ }^{5}$ Education \& ICT (E-Learning), \\ Universitat Oberta De Catalunya, \\ Barcelona, Spain \\ *These authors contributed equally to \\ this work
}

Correspondence: Muhammad Azeem Ashraf

Research Institute of Education Science, Hunan University, Changsha, Hunan,

People's Republic of China

Tel +86 I5600692980

Email azeem@hnu.edu.cn
Background: During the COVID-19 pandemic, there has been an increase in the use of digital platforms for educational purposes, and increased use of smartphones and social media has affected the academic performance of students. In this study, we explored how emotional intelligence can, directly and indirectly, influence academic performance, with academic social networking sites (ASNS) as a mediator.

Methods: A survey questionnaire comprising 42 items was used to collect data on emotional intelligence, ASNS, and academic performance. In total, 305 undergraduate university students participated in the study. Partial least squares structural equation modeling (SmartPLS-SEM 3.2.2) was used to measure the effects of emotional intelligence and ASNS. Results: Two dimensions of emotional intelligence, namely, self-regulation and selfawareness, showed significant positive effects on academic performance. Similarly, emotional intelligence and subscales of self-regulation, self-awareness and social skills showed a positive effect on ASNS. Likewise, ASNS showed a significant positive effect on academic performance. Looking at indirect influence, three dimensions of emotional intelligence, including self-regulation, self-awareness, and social skills, exerted a significant positive indirect influence on academic performance. Thus, outcomes of this study indicate that ASNS worked as a mediator between emotional intelligence and academic performance.

Conclusion: Emotional intelligence contributes directly and indirectly to increased academic performance. Together with emotional intelligence, ASNS played a positive and significant role in nurturing academic performance during the COVID-19 pandemic.

Keywords: higher education, self-regulation, self-awareness, motivation, social skills, academic social networking sites

\section{Introduction}

The foremost crisis faced in the world at present is the COVID-19 pandemic. Most countries have been forced to close their schools, colleges, and universities as they attempt to limit the spread of the virus. Policymakers face the dilemma of whether to close universities - thereby limiting social interaction to stop the outbreak - or keep them open, allowing employees to support students' quality learning. Face-toface teaching has been replaced with online learning in most countries, including Pakistan, and the suspension of face-to-face teaching has been a shock for both teachers and students. In Pakistan, university teaching has moved online through academic social networking sites (ASNS). ${ }^{1}$ This disrupted situation has created uncertainty in students' social lives. Students are more likely to experience 
depression, anxiety and reduced emotional well-being during the pandemic. ${ }^{2}$ University students may cope with this crisis by drawing on their emotional intelligence. ${ }^{3}$ There is, thus, a need to explore the role of emotional intelligence among undergraduate students during the pandemic.

The construct of emotional intelligence has significance in educational psychology, and works as a predictor of academic performance. Guided by this, educators have made decisions to improve students' academic performance. ${ }^{4,5}$ The emotional intelligence construct can be divided into two categories: personal and social attributes. Personal attributes are self-awareness, self-regulation, and motivation, while the social attribute is social skills. Self-awareness is recognizing and understanding one's own emotions and those of others. It refers to monitoring and identifying weaknesses, strengths, individual needs, and one's own emotions. Self-regulation directs and controls emotions positively, and allows individuals to withhold decisions until sufficient information is collected. The individual thinks carefully before action. ${ }^{6}$ Motivation helps students achieve their academic goals. ${ }^{7}$ Social skills attributes refer to students' cooperation, adjustment, relationship-building, and friendship-making - attributes that empower students to build strong links with their peer groups and teachers to enhance academic performance. ${ }^{8}$ Emotional intelligence plays a vital part in students' academic learning. Students with greater emotional intelligence are more self-confident in managing academic challenges. ${ }^{9}$ Therefore, emotional intelligence is considered a significant predictor of students' academic performance in higher education. ${ }^{4,5}$

Academic performance is a critical component of teaching and learning practices in higher education. A variety of academic performance indicators have been used by research scholars, such as "acquire knowledge and develop self-growth and skills", ${ }^{10}$ academic grades, ${ }^{11}$ life skills, ${ }^{12}$ cognitive skills, ${ }^{12}$ and study habits. ${ }^{12}$ Studies have shown that emotional intelligence and ASNS are important predictors of academic performance among students in higher education. ${ }^{13}$ Therefore, this study explored the direct and indirect role of ASNS in the academic performance of undergraduate students during the COVID-19 pandemic.

ASNS are considered to be central to teaching in higher education during the pandemic. ${ }^{14}$ ASNS support the interactions between teachers and students to ensure the teaching process runs smoothly. ${ }^{14,15}$ These sites also support the upkeep of online classes because face-to-face classes are not possible in this pandemic. ${ }^{16}$ We cannot overlook the importance of ASNS in higher education, as these skills can significantly influence overall academic performance. ASNS, together with other factors such as emotional intelligence, help enhance undergraduate students' academic performance during the pandemic. However, very few studies have investigated the effect of emotional intelligence on academic performance during the pandemic. ${ }^{17}$ It was assumed that students' emotional intelligence and ASNS are positively associated with academic performance. This study, therefore, measured the direct and indirect effects of emotional intelligence on academic performance, with ASNS studied as a mediator variable.

Literature has indicated the relationship between emotional intelligence, ASNS, and academic performance. ${ }^{13,18,19}$ Based on this, the study expected a mediating effect of ASNS between emotional intelligence and academic performance. Therefore, this study aimed to address these gaps in student involvement theory (Input-Environment-Output or I-E-O). We concentrated on intervening constructs of ASNS to provide new dimensions for student academic performance, with our research design enabling the following research questions:

RQ1: Does emotional intelligence affect undergraduate students' academic performance during the pandemic?

RQ2: Do emotional intelligence and ASNS affect students' academic performance during the pandemic?

\section{Literature Review}

\section{Emotional Intelligence}

Emotional intelligence is defined as the ability to deal with, identify, understand and express emotions. It refers to how emotions are applied in practical thinking and reasoning, and the positive regulation of emotions. ${ }^{20,21}$ Emotional intelligence includes self-awareness of emotions, self-regulation of emotions, motivation, and social skills. $^{9,22,23}$ Self-awareness is understanding one's own (and others') feelings. This emotional state explains why we feel emotions such as anger, frustration, and joy - and act accordingly. It also enhances thinking and fulfills nonemotional goals in this way. Self-regulation is the ability to cope with one's own emotions when interacting with peers and teachers. It is the ability to keep negative emotions at a manageable level. Motivation is the ability to use motivational strategies to stimulate student interest in learning 
topics. It also helps undergraduate students to achieve learning objectives. Social skills are the ability to understand others and build a positive relationship, especially with peer groups and teachers. ${ }^{23,24}$ They help students develop a conducive learning environment. In general, emotional intelligence facilitates face-to-face learning and learning through ASNS. ${ }^{25}$

\section{Academic Social Networking Sites}

ASNS have become important tools for facilitating the teaching-learning process. ${ }^{26}$ ASNS include applications and websites that allow students and teachers to exchange content, ideas, beliefs, concepts, and opinions, through social, individual, and educational involvement. They help academics to communicate with a wide range of users. $^{27,28}$ ASNS and the Internet are relatively costeffective channels for sharing information, knowledge, and learning. ${ }^{29,30}$ Instagram, Telegram, Facebook, Twitter, Skype, WhatsApp, Zoom, Google Meet, Gmail, and Wechat Work are the major ASNS/applications. ${ }^{31-33}$ Pakistan is a developing country where over 46 million social media users regularly use social applications. ${ }^{34}$ ASNS play a crucial role in the learning environment, reducing group interaction barriers and facilitating collaborative learning activities. ASNS encourage students to develop their self-learning and motivate them to learn from each other and their teachers. ${ }^{26}$ Social networking sites provide support for active and social learning, but at the same time can have some negative consequences for individuals, such as social networking addiction. ${ }^{35}$ ASNS have special academic features for collaborating, sharing knowledge, and learning actively. They are, therefore, considered more effective for learning than general social media sites, and are positively associated with student academic performance. ${ }^{26}$

\section{Academic Performance}

Academic performance is a relatively intuitive and frequently assumed predictor of learning outcomes. Operational definitions of academic performance vary across the literature. Grade point average (GPA) scores, typically calculated as a weighted average of all studied course grades, ${ }^{36}$ are frequently used as indicators of academic performance of undergraduate students. Some statistical limitations, such as range restriction, are yet to be addressed by GPA. ${ }^{37}$ Besides GPA, researchers use different operational definitions for academic performance, such as single subject performance, ${ }^{38}$ cognitive skills, ${ }^{38}$ self- growth, ${ }^{10}$ and study habits. ${ }^{12}$ These terms are most commonly considered alongside academic performance using GPA in various operational definitions in academic work. There is an explosion of curiosity in recent literature on the impact of emotional intelligence on academic performance. ${ }^{39}$ Conceptualization of the traits and skills associated with emotional intelligence has been given minimal systematic attention especially in terms of the relationship with academic performance. Moreover, academic performance is the ultimate outcomes of teaching learning process. We could find previous studies to investigate this normal situation, and we found no study which addresses this construct in COVID-19 pandemics. Therefore, this study investigates relationship of academic performance with EI and ASNS. The next part explains the relationship between the variables in our conceptual framework.

\section{Hypothesis Development and Theoretical Framework Emotional Intelligence and Academic Performance}

Educational studies have shed light on the positive and significant associations between emotional intelligence (including subscales of self-regulation, self-awareness, motivation, and social skills) and academic performance. ${ }^{7,9,39-41}$ Research has also been designed in higher education settings to evaluate the impact of emotional intelligence on students' academic performance. The findings have proved that emotional intelligence and academic performance have a significant positive association. $^{41,42}$ The theory of student involvement (I-E-O) supports the notion that emotional intelligence is highly significant for academic performance. ${ }^{43}$ The theory of student involvement also highlights mediating factors such as classroom engagement (online classroom engagement) between emotional intelligence and academic performance. ${ }^{13}$ Previous studies highlighted that students with higher emotional intelligence perform better in tests and achieve better results than those with lower emotional intelligence. $^{44}$ This may be because of better selfawareness of emotions, self-regulation, motivation, and social skills during their studies. ${ }^{45}$ These studies contribute to our understanding of the link between emotional intelligence (and its subscales) with academic performance. Therefore, a positive association between emotional 
intelligence with academic performance is predicted with the following hypotheses:

H1.1: Self-awareness positively influences academic performance

H1.2: Self-regulation positively influences academic performance

H1.3: Motivation positively influences academic performance

H1.4: Social skills positively influence academic performance.

\section{Emotional Intelligence and Academic Social Networking Sites}

Emotional intelligence is a critical factor that facilitates student engagement through ASNS during studies. The emergence of social networking sites and Internet technologies in recent years has facilitated and improved the quality of global communications in education. ${ }^{35,46}$ Moreover, the major factors of using social media are identified, such as professional usefulness, popularity, ethics, barriers, and innovativeness found a correlation among most of them, and further work was also suggested to explore social media usage construct. $^{46}$

It was recommended that the relationship between EI and usage of social media networks must be investigated further. Additionally, the contribution to the theory by using the concept of emotional intelligence in the context of social media need to be uncovered. ${ }^{35}$ Limited research has focused on exploring the association between emotional intelligence and ASNS. ${ }^{41}$ To address this gap, this study aimed to explore the positive relationship between emotional intelligence (self-awareness, self-regulation, motivation, and social skills) and ASNS. We developed the following hypotheses to explore the relationship of emotional intelligence with ASNS:

H2.1: Self-awareness positively influences academic social networking sites

H2.2: Self-regulation positively influences academic social networking sites

H2.3: Motivation positively influences academic social networking sites

H2.4: Social skills positively influence academic social networking sites.

\section{Academic Social Networking Sites and Academic Performance}

ASNS are positively associated with academic performance. ${ }^{47}$ ASNS also have diverse effects on academic performance when they fulfill non-academic and other social needs. ${ }^{48}$ Ravizza et $\mathrm{al}^{49}$ explored Internet use for non-academic activities. Social media use was negatively linked with university students' academic performance, as revealed in exams, especially three consecutive, cumulative final terms during the semester. Some researchers explored the advantages of using social media in learning processes. Twitter, for example, can be used for academic and extra-curricular debates and its use positively correlates with tertiary students' grades. ${ }^{50}$ Students who have higher engagement levels on social media obtained higher GPAs, while students with lower engagement levels attained lower GPA scores. Gregory et $\mathrm{al}^{51}$ suggested that Facebook use for instruction, especially the creation of groups for academic discussion of content and material out of class, could significantly enhance the engagement, satisfaction, and performance of students in higher education. Studies have shown that ASNS have a significant, positive relationship with academic performance. In line with this, the following hypothesis was proposed:

H3: Academic social networking sites positively influence academic performance.

\section{The Mediating Role of Academic Social Networking Sites}

Most literature indicates that emotional intelligence directly affects academic performance. ${ }^{9}$ However, social media engagement has been shown to positively mediate the association between emotional intelligence and academic performance. The impact of social media use on social and physical well-being and academic performance has been explored, and the results suggest a significant effect between the variables. ${ }^{52}$ Various studies have identified the gap in literature regarding the role social media networking sites improving the academic performance suggested to investigate the emotional intelligence with social media networking sites. ${ }^{35,46}$. To our knowledge, no study precisely addresses the mediating role of ASNS between emotional intelligence and academic performance. Thus, the study set out to explore the mediating 
role of ASNS between emotional intelligence and academic performance via the following hypotheses:

H4.1: Academic social networking sites positively mediate the relationship between self-awareness and academic performance

H4.2: Academic social networking sites positively mediate the relationship between self-regulation and academic performance

H4.3: Academic social networking sites positively mediate the relationship between motivation and academic performance

H4.4: Academic social networking sites positively mediate the relationship between social skills and academic performance.

\section{Conceptual Framework}

The present study proposed a model wherein emotional intelligence attributes could enhance academic performance through ASNS. Emotional intelligence is treated as a significant predictor of academic performance, ${ }^{42}$ and its positive influence on academic performance has been argued by several researchers. ${ }^{13,20,41}$ The I-E-O model contends that emotional intelligence attributes play a significant role in advancing academic performance. ${ }^{43}$ Emotional intelligence, together with ASNS, works as a tool for student motivation in challenging learning situations, helping to accelerate academic performance in the dynamic educational environment. The current study contends that ASNS mediates the effects between emotional intelligence and academic performance, and explores the ASNS mediation effect between emotional intelligence and academic performance. We analyzed this relationship and underline the impact of emotional intelligence on academic performance through ASNS during the COVID-19 pandemic in Pakistan. This study complements prior work by clarifying emotional intelligence attributes which, together with ASNS, lead to good academic performance. Figure 1 presents the proposed research model that summarizes all the study hypotheses.

\section{Research Methods}

The study took place in higher education settings in Pakistan, a developing country. To date, most studies focusing on emotional intelligence and academic performance have been in developed countries, with relatively little research conducted in developing countries where research is needed to obtain more diverse academic perspectives. Our motivation for this study is that the pandemic is a global issue, and needs to be acknowledged as such by considering knowledge and experiences from different perspectives and contexts. Most sectors continue to suffer due to the COVID-19 pandemic, with the badly affected higher education sector being no exception. The Pakistani higher education sector thus provides a suitable site for this study, as well as being easily accessible to the researchers. A survey was selected as the most appropriate method to access data for this study, and a questionnaire was developed for that purpose.

\section{Instrument Development}

This study used emotional intelligence dimensions (selfawareness, self-regulation, motivation, and social skills) as independent variables, academic performance as the dependent variable, and ASNS as a mediator. The first part of the questionnaire explained the study's purpose and provided instructions. This part also consisted of anonymity and privacy statements, and requested respondents' personal information, including gender, sector, and field of education. The second part described the items related to emotional intelligence (15 items), ASNS (10 items), and academic performance variables (17 items). All statements used a 7-point Likert scale (1: strongly disagree, to 7: strongly agree). Appendix 1 shows the questionnaire used for the study. Prior to the final data collection, the questionnaire's reliability and validity were checked by conducting a pilot study with 80 participants (30 from social sciences, 25 studying business sciences, and 25 in pure science fields). All participants in the pilot study shared similar demographics with the main study sample so that final data analysis could be trialed. The participants in the pilot study were aware of the study topic, and they suggested a few basic modifications to the questionnaire. We made changes following their feedback to ensure that all participants would understand all the items and be able to fill out the questionnaires successfully. The revised questionnaire was administered for final data collection.

\section{Variable Measurement Self-Awareness}

The items related to self-awareness were adapted from Zhoc $^{13}$ and Mehta and Singh. ${ }^{55}$ This section contained four items, with each item using a 7-point Likert-type scale, ranging from 1 (strongly disagree) to 7 (strongly agree). Items included: "I am able to identify my emotions 


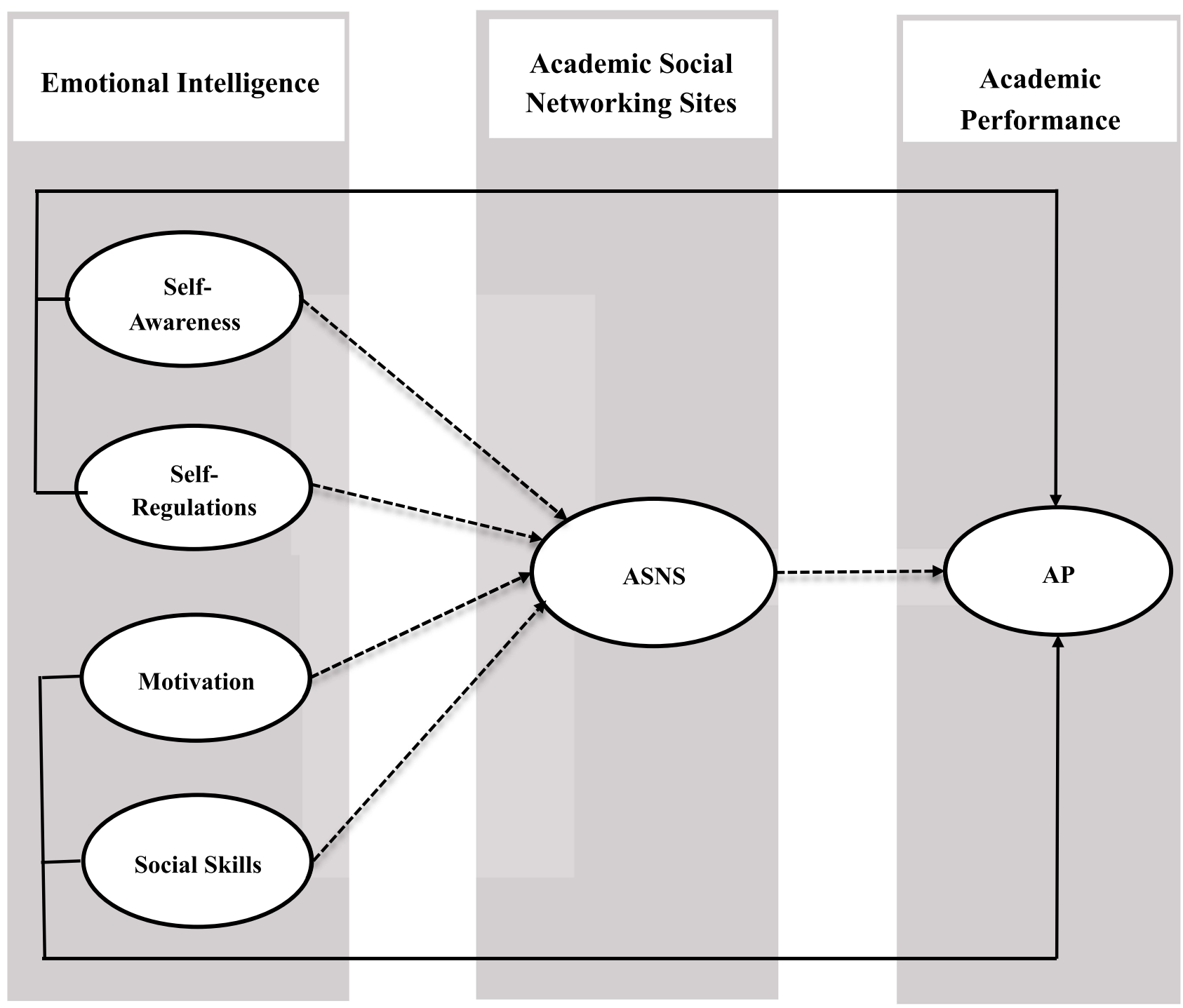

Figure I Research model.

Note: Dotted lines show indirect relationships, and solid lines show the direct relationship.

in different situations" and "I believe that emotions play an important role in everyday life events." Cronbach's alpha was 0.706 (Table 1).

\section{Self-Regulation}

Items were again modified from Zhoc, ${ }^{13}$ and Mehta and Singh. ${ }^{55}$ This section contained four items, and once again a 7-point Likert scale was used. Sample items included "I am able to control my overthinking" and "I concentrate on a pleasant activity when I am feeling low." Cronbach's alpha for self-awareness was 0.703 (Table 1).

\section{Motivation}

The four Likert scale items for motivation were taken and modified from Zhoc, ${ }^{13}$ and Mehta and Singh. ${ }^{55}$ Items included "I accept responsibility for my reactions" and "I direct my negative energy into doing something productive." Cronbach's alpha for motivation was 0.724 (Table 1).

\section{Social Skills}

Four social skills items were based on Zhoc, ${ }^{13}$ and Mehta and Singh. ${ }^{55}$ Using a 7-point Likert-type scale again, 1 represented strongly agree and 7 strongly disagree. A sample of items includes "I find it easy to share my feelings with others" and "It is easy for me to make friends." Cronbach's alpha for social skills was 0.706 (Table 1).

\section{Academic Social Networking Sites}

Some items related to ASNS were taken and modified from the work of Zhoc, ${ }^{13}$ while a smaller number were 
Table I Reliability and Convergent Validity

\begin{tabular}{|c|c|c|c|c|c|}
\hline Constructs & Factor Loading & Alpha & rho_A & CR & AVE \\
\hline Self-Awareness & & Original Sample: 0.706 & 0.749 & 0.818 & 0.534 \\
\hline SAI & 0.710 & Pilot study: 0.693 & & & \\
\hline SA2 & 0.861 & & & & \\
\hline SA3 & 0.751 & & & & \\
\hline SA4 & 0.570 & & & & \\
\hline Self-Regulation & & Original Sample: 0.703 & 0.735 & 0.809 & 0.519 \\
\hline SRI & 0.534 & Pilot Study: $0.7 \mathrm{II}$ & & & \\
\hline SR2 & 0.797 & & & & \\
\hline SR3 & 0.739 & & & & \\
\hline SR4 & 0.782 & & & & \\
\hline Motivation & & Original Sample: 0.724 & 0.729 & 0.799 & 0.570 \\
\hline MI & 0.790 & Pilot Study: 0.722 & & & \\
\hline M2 & 0.767 & & & & \\
\hline M3 & 0.707 & & & & \\
\hline Social Skill & & Original Sample: 0.706 & 0.755 & 0.816 & 0.531 \\
\hline SSI & 0.828 & Pilot Study:0.697 & & & \\
\hline SS2 & 0.695 & & & & \\
\hline SS3 & 0.815 & & & & \\
\hline SS4 & $0.54 I$ & & & & \\
\hline
\end{tabular}

Abbreviations: SA, self-awareness; SR, self-regulation; M, motivation; SS, social skills; Alpha, Cronbach's Alpha; CR, composite reliability; AVE, average variance extracted.

developed based on the literature review. ${ }^{56,57}$ This section contained ten items, and used a 7-point Likert-type scale ranging from 1 (strongly agree) to 7 (strongly disagree). Sample items included "Using email or other electronic means (such as WhatsApp, WeChat, Facebook) to share content with other students and teachers is very useful," "The e-learning platform (eg, Moodle, Zoom, WeChat work) is very useful to me," and "I use social media to disseminate knowledge to my classmates." Cronbach's alpha for ASNS was 0.787 .

\section{Academic Performance}

Here again, some items were taken and modified from Zhoc, ${ }^{13}$ while others were derived from the literature review. ${ }^{41,58}$ This section contained seventeen items that were rated on a 7-point Likert scale $(1=$ strongly agree; 7 = strongly disagree). Sample items included "I do my assignments independently" and "I have learned a new skill or knowledge by myself." Cronbach's alpha for academic performance was 0.702 .

\section{Sampling and Data Collection}

We collected data using a stratified random sampling technique, from undergraduates at public and private universities in the Lahore region of Pakistan. We applied stratified sampling technique to make sure the proportion of subgroups in sample that would enhance the precision in sample (representation) from subgroups of population. We attached a cover letter with the questionnaire that included information regarding the confidentiality of responses and assurance that the collected data would be used for research purposes only. The researchers visited sites personally to distribute the questionnaire in printed form to participants. We distributed 400 questionnaires among students in three major fields (social sciences, business sciences, and pure (natural) sciences), and received 305 useable responses. Further detail about the respondents is given in the next section. After completing the sampling and recruitment process, we proceeded with data analysis, described in greater detail in the data analysis section.

\section{Summary of Respondents}

Of the 400 questionnaires distributed, 395 completed questionnaires were returned. Of these, 90 were not useable and only 305 questionnaires were included for further analysis, giving a response rate of $76.25 \%$. The descriptive statistics show that the majority of respondents were male, ie, $56.7 \%$ males. A large proportion belonged to the private sector $(76.1 \%)$, and the rest were at public sector 
Table 2 Summary of Respondents

\begin{tabular}{|l|l|c|c|}
\hline Characteristics & Categories & Frequency (n) & Percentage (\%) \\
\hline Gender & Male & 173 & 56.7 \\
& Female & 132 & 43.3 \\
& Total & 305 & 100.0 \\
\hline \multirow{2}{*}{ Sector } & Public & 99 & 23.9 \\
& Private & 206 & 76.1 \\
& Total & 305 & 100.0 \\
\hline \multirow{2}{*}{ Field of Study } & Social & 141 & 46.2 \\
& Sciences & & 22.0 \\
& Business & 67 & 31.8 \\
& Sciences & & 100.0 \\
& Pure & 97 & \\
& Sciences & & \\
& Total & 305 & \\
& & &
\end{tabular}

institutions (23.9\%). Respondents' study fields were social sciences (46.2\%), business sciences (22.0\%), and pure sciences $(31.8 \%)$. Table 2 provides a detailed summary of respondents.

\section{Results}

\section{The Measurement Model}

The study used SmartPLS 3.2.2 for structural equation modeling (SEM) to measure the relationship among variables defined in the research model. ${ }^{59}$ SmartPLS 3.2.2 software was chosen as it is more statistically efficient and relatively less sensitive to the size of the sample compared with other software used for covariance-based SEM. $^{60}$ This research measured the association between emotional intelligence, ASNS, and undergraduate students' academic performance during the pandemic. Thus, prior to testing the hypothesized influences, we examined the validity and reliability of constructs in the model.

Table 1 shows the validity and reliability of the constructs. The reliability index of loading factors of each item is higher than the threshold value of 0.60 (factor loading value more than 0.50 is also acceptable if the average variance extracted is above 0.50). Similarly, other reliability tests such as Cronbach's alpha, composite reliability, and rho_A have greater values than the recommended $0.70 .^{59,60}$ The AVE (average variance extracted) approach was applied for measuring the convergent validity of reflective constructs. The AVE values for each of the constructs were more than the standard value of $0.50 .{ }^{61}$ This study measured the reliability and convergent validity of all reflective constructs used in the research model. The
AVE square root for each construct was greater than the shared variance among constructs. Therefore, the requirements of reliability and validity were fulfilled.

Henseler and Ringle criticized the Fornell and Larcker measurement approach, stating it is an unreliable method for measuring discriminant validity. ${ }^{59}$ They recommended a heterotrait-monotrait (HTMT) approach to test discriminant validity in partial least squares SEM. ${ }^{59}$ We applied this technique to measure discriminant validity, which is considered more appropriate technique to measure discriminant validity. The HTMT approach is defined as the item correlation among constructs with the correlations within items of the same construct. Henseler, Ringle, and Sarstedt ${ }^{60}$ proposed that the standard value of HTMT is less than $0.90 .^{59,62}$ Therefore, HTMT values exceeding 0.90 would indicate that the construct has poor discriminant validity. Table 3 indicates that each construct's HTMT value is less than 0.90. Therefore, the scale fulfilled the requirements of discriminant validity.

The convergent validity was measured through redundancy analysis, collinearity, and potential collinearity problems when VIF $\geq 3-5$, preferably indicating VIF $<3$. Moreover, the statistical significance of weighted $p$-value $<0.05$ was measured. The non-significant weight loading of 0.50 or more at the indicators is considered essential. ${ }^{59}$

We used these approaches to analyze the formative measurement model. Table 4 indicates formative measurement analysis as redundancy, collinearity, statistical significance, and indicator weight. All these indicators' values meet the standard values. Therefore, the formative

Table 3 Discriminant Validity (HTMT)

\begin{tabular}{|l|c|c|c|c|}
\hline Reflective Measures & M & SA & SR & SS \\
\hline Motivation (M) & & & & \\
Self-Awareness (SA) & 0.596 & & & \\
Self-Regulation (SR) & 0.622 & 0.464 & & \\
Social Skill (SS) & 0.588 & 0.622 & 0.639 & \\
\hline
\end{tabular}

Abbreviation: HTMT, heterotrait-monotrait.

Table 4 Validity and Reliability of the Formative Construct

\begin{tabular}{|l|c|c|c|c|}
\hline $\begin{array}{l}\text { Formative } \\
\text { Measures }\end{array}$ & $\begin{array}{c}\text { Redundancy } \\
(\mathbf{r})\end{array}$ & VIF & $\begin{array}{c}\text { Indicator } \\
\text { Weights }\end{array}$ & $\boldsymbol{P}$ values \\
\hline $\begin{array}{l}\text { Academic Social } \\
\text { Networking Sites } \\
\text { Academic } \\
\text { Performance }\end{array}$ & 1.000 & 1.000 & 1.000 & 0.000 \\
\hline
\end{tabular}

Abbreviation: VIF, variance inflation factor. 
measurements of both constructs (ASNS and academic performance) were found to be reliable and valid (see Figures 2 and 3).
We used descriptive statistical analysis to measure students' emotional intelligence (on subscales of selfawareness, self-regulation, motivation and social skills),

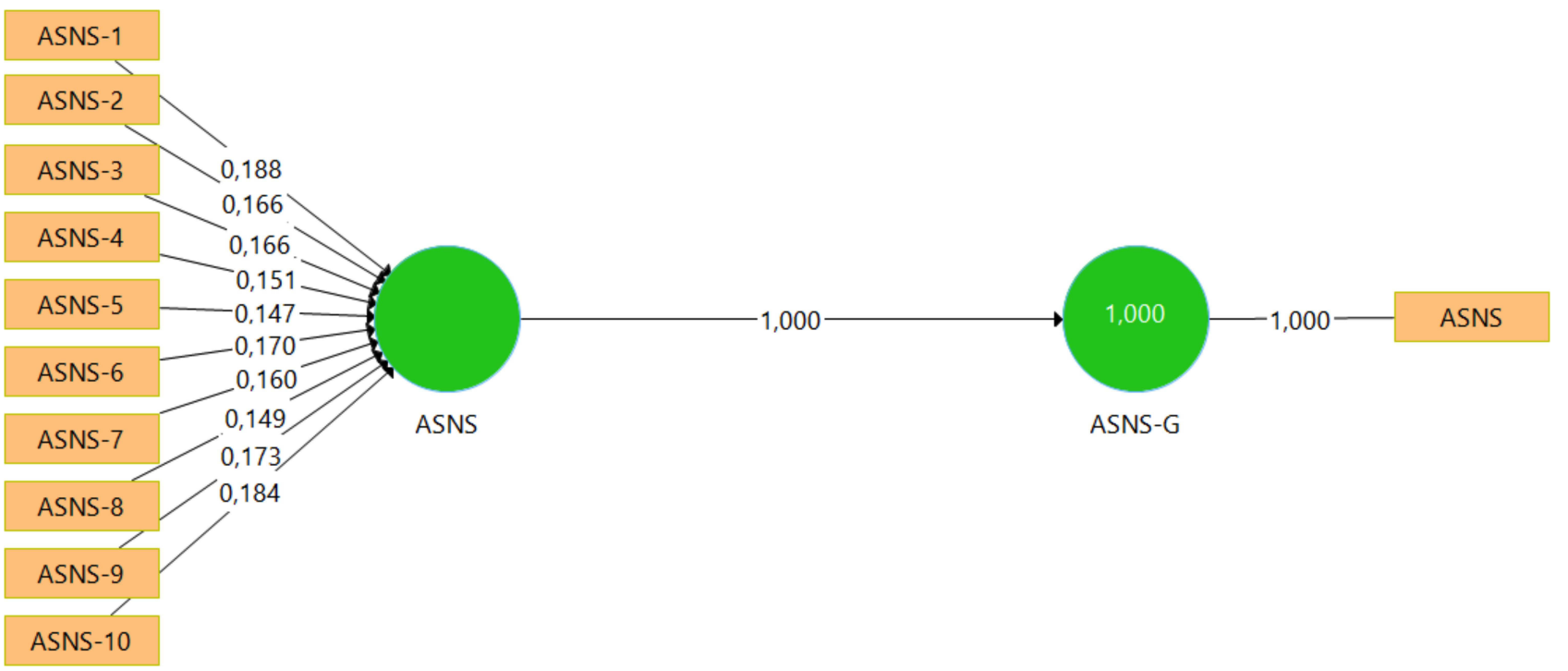

Figure 2 Formative construct of Academic Social Networking Sites (ASNS) used in theoretical analysis with Global Items.

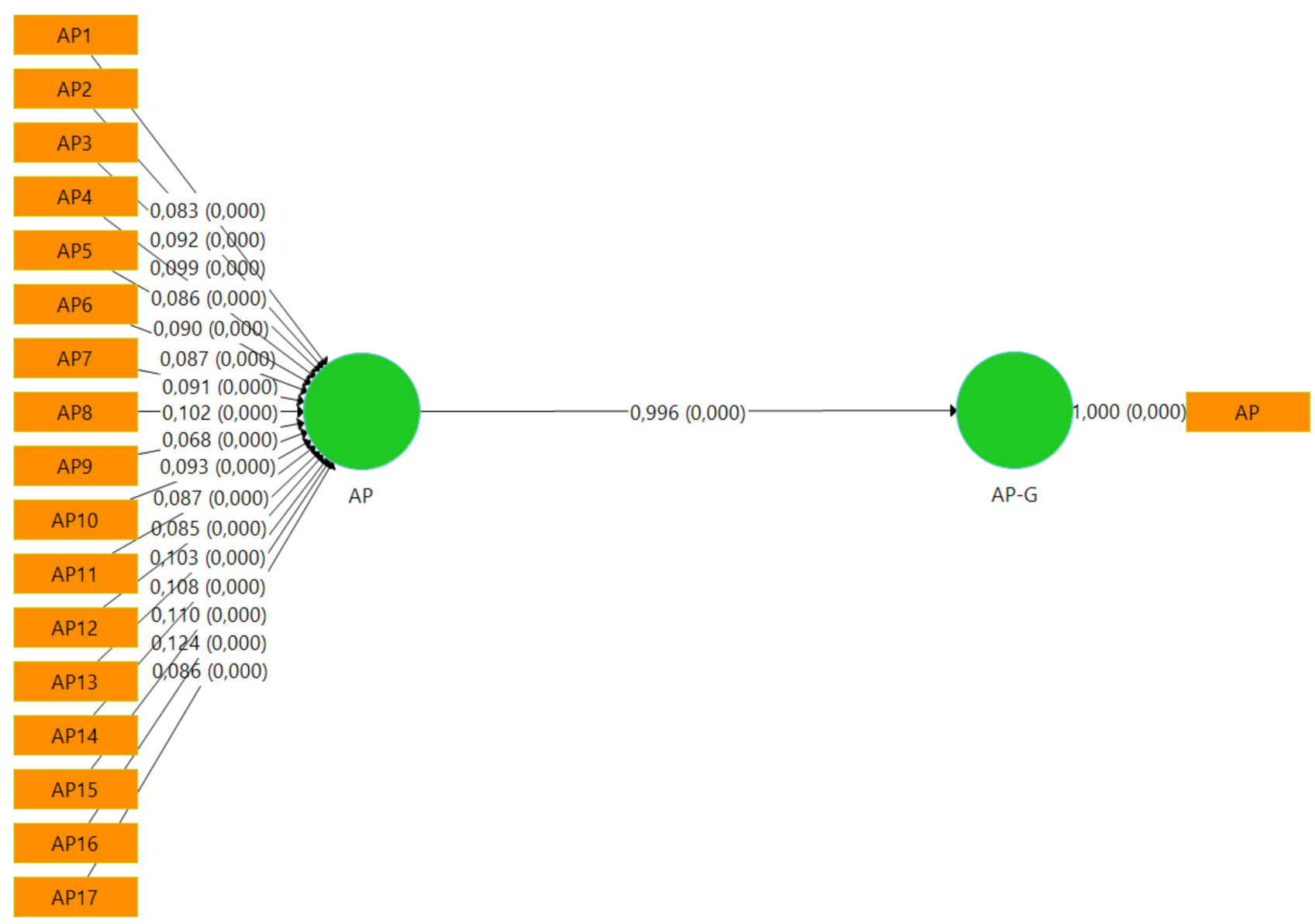

Figure 3 Formative construct of Academic Performance (AP) used in theoretical analysis with Global Items. 
Table 5 Descriptive Analyses

\begin{tabular}{|c|c|c|c|c|c|}
\hline Measures & $\mathbf{N}$ & Minimum & Maximum & Mean & Std. Deviation \\
\hline Self-awareness & 305 & 1.00 & 7.00 & 5.213 & 1.270 \\
\hline Self-regulation & 305 & 1.00 & 7.00 & 4.826 & 1.248 \\
\hline Motivation & 305 & 1.17 & 7.00 & 4.855 & $\mathrm{I} .105$ \\
\hline Social Skill & 305 & 1.00 & 7.00 & 5.150 & $\mathrm{I} .26 \mathrm{I}$ \\
\hline Academic Social Networking Sites & 305 & 1.90 & 7.00 & 4.893 & 1.017 \\
\hline Academic Performance & 305 & $\mathrm{I} .74$ & 6.84 & 5.126 & 0.928 \\
\hline
\end{tabular}

ASNS, and academic performance. All scales were divided into seven levels (1-7) from lowest to highest. Table 5 shows the results of ASNS usage and academic performance. Participants had a high level of emotional intelligence with a range of mean scores from 4.826 to 5.213. The mean score for ASNS (4.893) indicates high use of such sites. The mean academic performance score (5.126) indicates that students were performing well.

\section{Structural Model}

This study used SmartPLS-SEM 3.2.2 to measure the relationships between variables in the research model. ${ }^{62}$ Partial least square is the variance-based structural equation modeling (VB-SEM) technique that facilitates the concurrent assessment of the measurement model. This approach helps to test the validity and reliability of the scales used in the research model. In the structural model, we analyzed the relationships hypothesized among constructs comprising the model. ${ }^{54,63}$ Table 6 indicates the direct influences of the nine constructs. The four emotional intelligence constructs directly influence academic performance. Furthermore, selfawareness has a significant positive relationship with academic performance $(\beta=0.151, p<0.05)$, which supports hypothesis H1.1. Similarly, self-regulation has a significant positive effect on academic performance $(\beta=0.153, p>$
0.05), which does not support hypothesis H1.2. Motivation positively influences the academic performance $(\beta=0.153$, $p<0.05)$ supporting hypothesis H1.3. Social skills have a significant positive relationship with academic performance $(\beta=0.142, p>0.05)$ that does not support hypothesis H1.4. All four emotional intelligence constructs (selfawareness, self-regulation, motivation, and social skills) have a significant positive relationship with academic performance.

Self-awareness has a significant positive correlation with ASNS $(\beta=0.228, p<0.05)$, supporting hypothesis H2.1. Further, self-regulation has a significant positive relationship with ASNS $(\beta=0.190, p<0.05)$, which supports hypothesis H2.2. Motivation also has a significant positive relationship with ASNS $(\beta=0.100$, $p>0.05$ ), which does not support hypothesis H2.3. Social skills have a significant positive relationship with ASNS ( $\beta$ $=0.264, p<0.05$ ), which affirms hypothesis H2.4. Similarly, ASNS have a significant positive relationship with academic performance $(\beta=0.346, p<0.05)$, resulting in acceptance of hypothesis $\mathrm{H} 3$.

\section{Mediating Effect}

We tested the mediating effect of ASNS between emotional intelligence (self-awareness, self-regulation,

Table 6 Direct Relations Between the Research Constructs

\begin{tabular}{|l|c|c|c|c|c|c|}
\hline Direct Relations & Coefficient & Means & Standard Deviation & T Statistics & P values & Results \\
\hline SA -> AP & 0.151 & 0.149 & 0.068 & 2.205 & 0.028 & Sig \\
SR -> AP & 0.153 & 0.146 & 0.079 & 1.947 & 0.052 & Insig \\
M -> AP & 0.153 & 0.150 & 0.069 & 2.223 & 0.026 & Sig \\
SS -> AP & 0.142 & 0.145 & 0.073 & 1.937 & 0.053 & Insig \\
SA -> ASNS & 0.228 & 0.234 & 0.063 & 3.630 & 0.000 & Sig \\
SR -> ASNS & 0.190 & 0.198 & 0.066 & 2.866 & 0.004 & Sig \\
M -> ASNS & 0.100 & 0.106 & 0.059 & 1.691 & 0.091 & Insig \\
SS -> ASNS & 0.264 & 0.261 & 0.071 & 3.705 & 0.000 & Sig \\
ASNS -> AP & 0.346 & 0.372 & 0.063 & 5.516 & 0.000 & Sig \\
\hline
\end{tabular}

Abbreviations: SA, self-awareness; SR, self-regulation; M, motivation; SS, social skills; ASNS, academic social networking sites; AP, academic performance. 
Table 7 Indirect Relations Between the Research Constructs

\begin{tabular}{|l|c|c|c|c|c|c|}
\hline Indirect Relations & Coefficient & Means & Standard Deviation & T Statistics & P values & Results \\
\hline SA -> ASNS -> AP & 0.079 & 0.087 & 0.028 & 2.810 & 0.005 & Sig \\
SR -> ASNS -> AP & 0.066 & 0.074 & 0.029 & 2.299 & 0.022 & Sig \\
M -> ASNS -> AP & 0.034 & 0.039 & 0.023 & 1.515 & 0.130 & Insig \\
SS -> ASNS -> AP & 0.091 & 0.097 & 0.031 & 2.931 & 0.003 & Sig \\
\hline
\end{tabular}

Abbreviations: SA, self-awareness; SR, self-regulation; M, motivation; SS, social skills; ASNS, academic social networking sites; AP, academic performance.

motivation, and social skills) and undergraduate students' academic performance. Table 7 shows that an indirect relationship was found for self-awareness ( $\beta=0.079, p<$ $0.05)$, self-regulation $(\beta=0.066, p<0.05)$, motivation $(\beta=$ $0.034, p>0.05)$, and social skills $(\beta=0.091, p<0.05)$ on academic performance. Hence, ASNS was shown to have significantly and positively mediated between selfawareness, self-regulation, and social skills, supporting our hypotheses H4.1, H4.2, and H4.4. As ASNS was not a significant, positive mediator between motivation and academic performance, hypothesis H4.3 was not supported.

Self-awareness and self-regulation both exerted significant direct and indirect effects, translating to partially mediated effects between significant self-awareness and self-regulation on academic performance through ASNS. However, motivation was found to have a significant direct effect on academic performance and was not found to have a significant indirect relationship with academic performance, meaning no mediated effects of self-awareness on academic performance through ASNS. Lastly, the social skills variable was not found to have a significant, direct relationship with academic performance. However, it was found to have a significant indirect influence on academic performance, which translated to full mediation between self-awareness and academic performance through ASNS. Figure 4 demonstrates more details of the relationships between theoretical constructs with $\mathrm{R}^{2}$ values.

Decisions related to coefficient $\mathrm{R}^{2}$ are based on the threshold values of $0.75,0.50$, and 0.25 , regarded as substantial, modest, and weak correlation levels. These are the core criteria for assessing correlation strength in SEM. The $\mathrm{R}^{2}$ threshold value of 0.90 and above was deemed a significant indicator of over-fitting. The $\mathrm{R}^{2}$ excluded

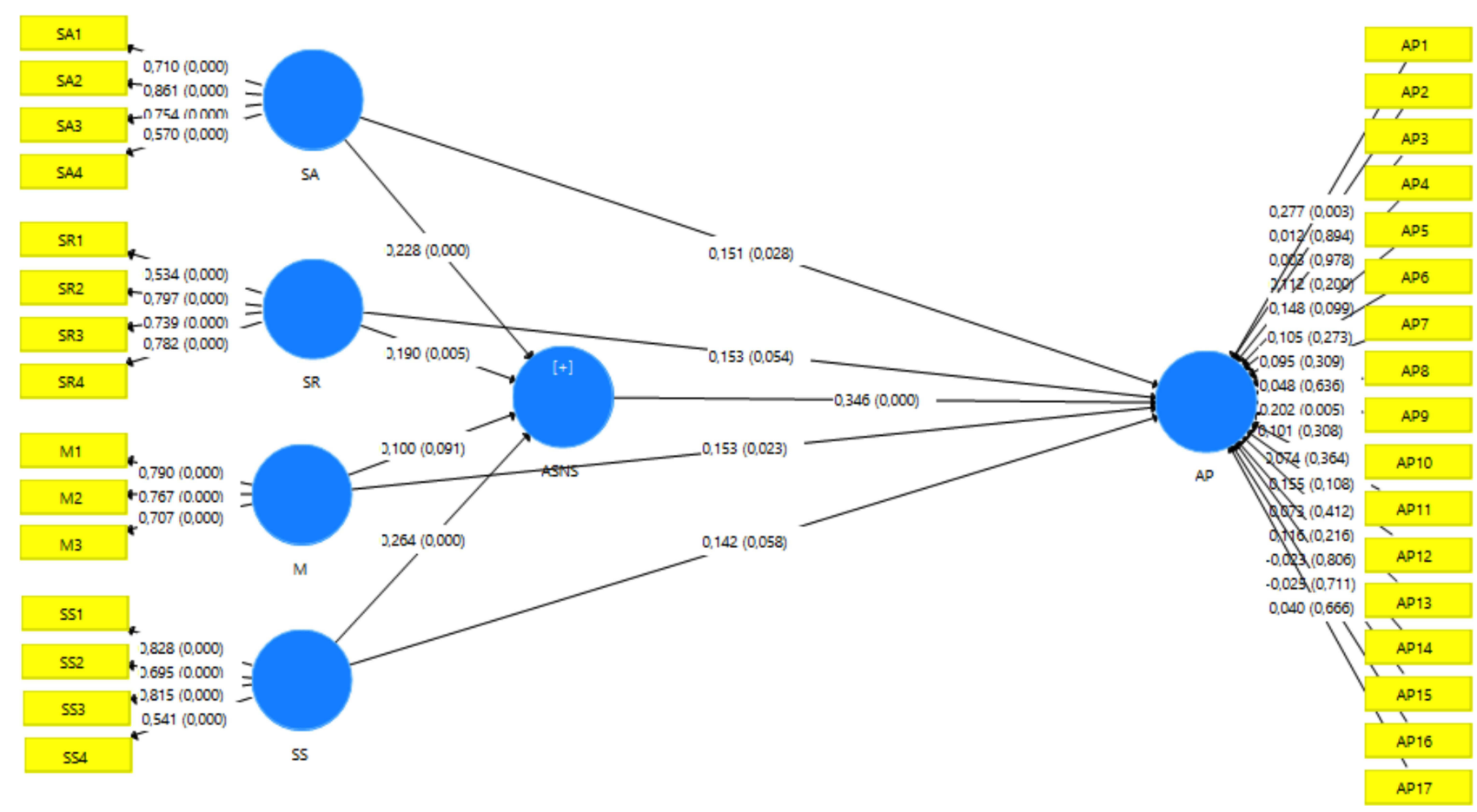

Figure 4 Theoretical constructs with $\mathrm{R}^{2}$ values in output model. 
value for self-awareness is 0.228 , for self-regulation 0.190 , and for motivation 0.100 . The $\mathrm{R}^{2}$ excluded value for $\mathrm{SS}$ is 0.264, and for ASNS 0.346. Estimations of all subscales were found to be significant and correlated with dependent variables in the output model.

\section{Discussion}

This study focused on the relationship between emotional intelligence and ASNS, and academic performance. The results indicate a meaningful relationship between these variables based on the research model. To date, most research of this nature has been done in developed countries ${ }^{11,20,64}$ and, before the current pandemic, limited research considered developing countries like Pakistan. ${ }^{65}$ To the authors' best knowledge, this is the first study to explore the influence of emotional intelligence and ASNS on academic performance in the COVID-19 situation in the Pakistani context, particularly in considering ASNS as a mediating variable.

The study first focused on the direct connection between emotional intelligence and academic performance during the pandemic. The results indicated that emotional intelligence (self-awareness and motivation) significantly influences academic performance, and the results partially support our hypotheses H1.1 and H1.4. Previous studies have shown that emotional intelligence has a significant and positive effect on academic performance. ${ }^{41,42}$ Najafi $^{66}$ conducted a survey in Iran with 343 Payame Noor University faculty members and found that emotional intelligence has a positive and significant relationship with academic performance. Therefore, it seems possible that emotional intelligence is a predictor of undergraduate students' academic performance during the pandemic.

Second, the study examined the direct relationship between emotional intelligence and ASNS. The results indicate that emotional intelligence (self-awareness, selfregulation, and social skills) has a positive and significant relationship with ASNS, which partially supported our hypotheses H2.1 and H2.4. Studies have shown that emotional intelligence and social networking sites influence each other positively. ${ }^{46}$ Mursidi et $\mathrm{al}^{67}$ conducted a survey of prospective teachers in Indonesia. The results indicated that emotional intelligence and social media usage have a positive relationship, helping online teaching. In contrast, a survey of 130 university students in Patiala found that emotional intelligence and social media usage do not have a significant relationship. ${ }^{68}$ Our study was different as it was conducted during the pandemic, and emotional intelligence and social media networking were positively associated with each other. Therefore, emotional intelligence may have become an essential tool for practical use of ASNS and facilitating the learning process.

Third, this study investigated the direct influence of ASNS on students' academic performance. The study showed that ASNS have a significant and positive effect on students' academic performance, supporting hypothesis H3. Prior studies have also shown that positive use of ASNS has a positive influence on student academic performance. ${ }^{69,70} \mathrm{~A}$ cross-sectional study of medical students measured the relationship between social media usage and academic performance, and found that those students who use social media with guidelines performed well in their academic work. ${ }^{71}$ On the other hand, a study ${ }^{72}$ of university students in the Middle East investigated the impact of social media sites such as Facebook on students' academic performance. The results indicated that students' social media use has a negative influence on their academic performance. Here the result might be different due to a lack of guidelines for students regarding the positive use of social media. Moreover, this current study was conducted in 2021 when the COVID-19 pandemic was at peak level, so those specific circumstances may have led to a difference in the results. The COVID-19 pandemic may force students towards effective use of ASNS for their academic purposes.

Fourth, the study measured the indirect effect of emotional intelligence and its subscales on academic performance. The results confirmed that ASNS significantly and positively mediate between emotional intelligence (selfawareness, self-regulation, and social skills) and academic performance, partially supporting our hypotheses H4.1 and H4.4. Previous research also confirmed that controlled use of social networking sites mediates between emotional intelligence and academic performance. ${ }^{73}$ Desmal $^{74}$ conducted a survey of 150 students at three universities in Bahrain to measure the effect of social networking sites on academic performance. The results confirmed that use of sites such as Instagram, Facebook and Twitter is correlated with student emotional intelligence and academic performance. This current study also indicated that ASNS, such as Zoom, WeChat work, Google meet and Gmail, mediate between emotional intelligence and academic performance at the undergraduate level during the pandemic.

\section{Conclusions}

This study designed a research model based on prior literature and student involvement theory, ${ }^{43}$ to explore 
the relationship between emotional intelligence and academic performance. The results confirmed the direct and indirect relationship of emotional intelligence with academic performance during the COVID-19 pandemic in Pakistan. This study revealed that three emotional intelligence subscales (self-awareness, self-regulation, and motivation) have a direct, positive and significant effect on students' academic performance. One emotional intelligence subscale (social skills) had no significant influence on academic performance although a direct relationship could be demonstrated. We also measured the direct relationship of emotional intelligence with ASNS, and results indicated that self-awareness, self-regulation, and social skills have a direct, positive, and significant link with ASNS. Motivation does not have a significant, positive relationship with ASNS.

This study measured ASNS' direct relationship with academic performance. The results indicated that ASNS have a direct significant and positive relationship with academic performance. Similarly, our study revealed that emotional intelligence has a significant positive indirect relationship with academic performance, and ASNS has a mediating role between emotional intelligence (selfawareness, self-regulation, and social skills) and academic performance during the pandemic in Pakistan. One other result indicated that the ASNS do not have a significant mediating role between the emotional intelligence subscale of motivation and academic performance.

The following conclusions thus arise from the study: First, self-awareness of emotions is a predictor of academic performance of undergraduate students. Having this awareness helps the students comprehend their emotional states to build better relationships with others and support consistent improvement of their academic performance. Selfregulation is an emotional trait linked to academic performance that helps the students control their emotions and adjust them positively in challenging situations, ultimately increasing academic performance. Motivation has a direct and positive association with academic performance. It provides support and encouragement to the students to work harder to improve their academic performance. Moreover, emotional intelligence (self-awareness, selfregulation, and social skills) is positively supported by ASNS used in the pandemic. Positive use of ASNS is a predictor of students' academic performance at the undergraduate level in universities of Pakistan during the pandemic. Lastly, we concluded that emotional intelligence, such as self-awareness, self-regulation, and social skills together with the use of ASNS, could facilitate increased academic performance during the pandemic.

\section{Implications}

Emotional intelligence and ASNS are key predictors of academic performance. There are implications for different stakeholders such as teachers, curriculum developers, and university management. First, teachers can identify students at risk for failure or underperformance and provide them with training to improve their emotional intelligence. Curriculum developers should prepare an emotional intelligence curriculum to teach the students who are at risk for failure or underperformance. Universities' human resource management departments should hire counselors to provide counseling services to those students who need them. In the current situation, most academic activities are being performed online. Thus, teachers must be trained to help students control their negative use of ASNS, and provide them with guidelines for constructive ASNS use to accelerate academic performance. Moreover, university management could advise the curriculum designers to develop a specific course focused on improvement of students' emotional intelligence during this pandemic.

\section{Limitations and Future Research}

The scope of the study was limited due to a focus on higher education in Pakistan only. Further research could be conducted in areas such as elementary and secondary school education to enable better understanding of the phenomena under study. Another limitation was the moderate response rate of the survey respondents. Future research with a higher response rate may help produce more reliable insights. We did not include medical students as participants. Future studies that include medical students would also be valuable in exploring the relationship between the variables.

\section{Ethics Statement}

This study is part of a large research project supported by the National Natural Science Foundation of China (Grant No. 71950410624). The principal investigator of this project is currently working at Hunan University. The ethics committee of Hunan University approved the study, and authors confirm that the study was conducted in accordance with Helsinki Declaration, revised in 2013. The study used a survey method to collect data, and each participant signed an informed consent form prior to participating. Further, permission was obtained from all participating institutions. 


\section{Acknowledgments}

The study was supported by the National Natural Science Foundation of China (Grant No. 71950410624). However, any opinions, findings, and conclusions or recommendations expressed in this article are those of the author(s) and do not necessarily reflect the views of the National Natural Science Foundation of China.

\section{Disclosure}

The authors report no conflicts of interest in this work.

\section{References}

1. Gonzalez T, De La Rubia M, Hincz KP, et al. Influence of COVID-19 confinement on students' performance in higher education. PLoS One. 2020;15(10):e239490. doi:10.1371/journal. pone. 0239490

2. Charoensukmongkol P, Phungsoonthorn T. The effectiveness of supervisor support in lessening perceived uncertainties and emotional exhaustion of university employees during the COVID-19 crisis: the constraining role of organizational intransigence. J Gen Psychol. 2020:1-20.

3. Charoensukmongkol P, Phungsoonthorn T. The interaction effect of crisis communication and social support on the emotional exhaustion of university employees during the COVID-19 crisis. Int J Bus Commun. 2020:2329488420953188.

4. Ali HS, Mohammed QQ. Influence of emotional intelligence on academic achievement among students at secondary schools in Babylon City. Indian J Med Forensic Med Toxicol. 2020;14(1).

5. Goh E, Kim HJ. Emotional intelligence as a predictor of academic performance in hospitality higher education. J Hosp Tour Educ. 2020:1-7.

6. Raghubir AE. Emotional intelligence in professional nursing practice: a concept review using Rodgers's evolutionary analysis approach. Int J Nurs Sci. 2018;5(2):126-130. doi:10.1016/j.ijnss.2018.03.004

7. Ranasinghe P, Wathurapatha W, Mathangasinghe Y, Ponnamperuma G. Emotional intelligence, perceived stress and academic performance of Sri Lankan medical undergraduates. BMC Med Educ. 2017;17(1):1-7. doi:10.1186/s12909-017-0884-5

8. Nikooyeh E, Zarani F, Fathabadi J. The mediating role of social skills and sensation seeking in the relationship between trait emotional intelligence and school adjustment in adolescents. $J$ Adolesc. 2017;59:45-50. doi:10.1016/j.adolescence.2017.05.012

9. Jan SU, Anwar MA. Emotional intelligence, library use and academic achievement of university students. J Aust Lib Inf Assoc. 2019;68 (1):38-55. doi:10.1080/24750158.2019.1572482

10. Alamri MM, Almaiah MA, Al-Rahmi WM. Social media applications affecting students' academic performance: a model developed for sustainability in higher education. Sustainability. 2020;12 (16):6471. doi:10.3390/su12166471

11. Zhoc KC, Webster BJ, King RB, Li JC, Chung TS. Higher education student engagement scale (HESES): development and psychometric evidence. Res High Educ. 2019;60(2):219-244. doi:10.1007/s11162018-9510-6

12. Tus J. The influence of study attitudes and study habits on the academic performance of the students. Int $\mathrm{J}$ All Res Writings. I2020;2(4):11-32 |.

13. Zhoc CH Study on the interrelationships between emotional intelligence, self-directed learning and the first year student engagement in the Hong Kong context [Thesis]. Pokfulam, Hong Kong SAR: University of Hong Kong; 2015. doi:10.5353/ th_b5481897.
14. Cavus N, Sani AS, Haruna Y, Lawan AA. Efficacy of social networking sites for sustainable education in the era of COVID-19: a systematic review. Sustainability. 2021;13(2):808. doi:10.3390/ su13020808

15. Tsovaltzi D, Judele R, Puhl T, Weinberger A. Scripts, individual preparation and group awareness support in the service of learning in Facebook: how does CSCL compare to social networking sites? Comput Human Behav. 2015;53:577-592. doi:10.1016/j.chb.2015.04.067

16. Lin L, Shek DTL. Serving children and adolescents in need during the COVID-19 Pandemic: evaluation of service-learning subjects with and without face-to-face interaction. Int $J$ Environ Res Public Health. 2021;18(4):2114. doi:10.3390/ijerph18042114

17. Chandra Y. Online education during COVID-19: perception of academic stress and emotional intelligence coping strategies among college students. Asian Educ Dev Studies. 2021;10(2):229-238. doi:10.1108/AEDS-05-2020-0097

18. Chawinga WD. Taking social media to a university classroom: teaching and learning using Twitter and blogs. Int J Educ Technol High Educ. 2017;14(1):1-19. doi:10.1186/s41239-017-0041-6

19. Alt D. Students' wellbeing, fear of missing out, and social media engagement for leisure in higher education learning environments. Curr Psychol. 2018;37(1):128-138. doi:10.1007/s12144-016-9496-1

20. Moroń M, Biolik-Moroń M. Trait emotional intelligence and emotional experiences during the COVID-19 pandemic outbreak in Poland: a daily diary study. Pers Individ Dif. 2021;168:110348. doi:10.1016/j.paid.2020.110348

21. Mayer JD, Salovey P. What is emotional intelligence. In: Salovey P, Sluyter D J, editors. Emotional Development and Emotional Intelligence: Educational Implications. ; New York: Basic Books; 1997:3-31.

22. Norboevich TB. Analysis of psychological theory of emotional intelligence. Eur J Res Reflect Educ Sci. 2020;8(3):99-104.

23. Boyatzis RE, Goleman D, Rhee K. Clustering competence in emotional intelligence: insights from the Emotional Competence Inventory (ECI). Handb Emotional Intell. 2000;99(6):343-362.

24. Pekrun R, Stephens EJ. Achievement emotions in higher education. In: Smart J, editors. Higher Education: Handbook of Theory and Research. Springer. 2010:257-306.

25. Gorgas DL, Greenberger S, Bahner DP, Way DP. Teaching emotional intelligence: a control group study of a brief educational intervention for emergency medicine residents. West J Emerg Med. 2015;16 (6):899. doi:10.5811/westjem.2015.8.27304

26. Azizi SM, Soroush A, Khatony A. The relationship between social networking addiction and academic performance in Iranian students of medical sciences: a cross-sectional study. BMC Psychol. 2019;7 (1):1-8. doi:10.1186/s40359-019-0305-0

27. Alahmar AT. The impact of social media on the academic performance of second year medical students at College of Medicine, University of Babylon, Iraq. J Med Allied Sci. 2016;6(2):77. doi:10.5455/jmas.236927

28. Błachnio A, Przepiorka A, Pantic I. Association between Facebook addiction, self-esteem and life satisfaction: a cross-sectional study. Comput Human Behav. 2016;55:701-705. doi:10.1016/j.chb.2015.10.026

29. de Hond M, Rood T. Flip the school, forget the classroom: how to enable personalised learning with the help of information technology. In: MarcusQuinn A, Hourigan T, editors. Handbook on Digital Learning for K-12 Schools. Springer; 2017:317-328.

30. Zarlis M, Mawengkang H, Sembiring R The role of information and communication technology in developing smart education. Paper presented at: Journal of Physics: Conference Series; 2017.

31. Kuss DJ, Griffiths MD. Social networking sites and addiction: ten lessons learned. Int J Environ Res Public Health. 2017;14(3):311. doi:10.3390/ijerph14030311

32. Ebrahimpour A, Rajabali F, Yazdanfar F, et al. Social network sites as educational factors. Acta Inform Med. 2016;24(2):134. doi:10.5455/ aim.2016.24.134-138 
33. Wagenseil P. Zoom security issues: here's everything that's gone wrong (so far). Tom's Guide. 2020;11.

34. Kemp S. Digital 2021: Pakistan 2021; 2021. Available from: https:// datareportal.com/reports/digital-2021-pakistan\#: :text=Social\% 20media\%20statistics\%20for\%20Pakistan,total\%20population $\% 20$ in \%20January\%202021. Accessed April 14, 2021.

35. Avcı K, Çelikden SG, Eren S, Aydenizöz D. Assessment of medical students' attitudes on social media use in medicine: a cross-sectional study. BMC Med Educ. 2015;15(1):1-6. doi:10.1186/s12909-015-0300-y

36. Yigermal ME. The determinants of academic performance of under graduate students: in the case of Arba Minch University Chamo Campus. Online Submission. 2017;3(4):35-42.

37. John R, John R. The Big Five personality traits and academic performance. J Law Soc Stud. 2020;2(1):10-19. doi:10.52279/ jlss.02.01.1019

38. Furnham A, Chamorro-Premuzic T, McDougall F. Personality, cognitive ability, and beliefs about intelligence as predictors of academic performance. Learn Individ Differ. 2003;14(1):47-64. doi:10.1016/j. lindif.2003.08.002

39. Perera HN, DiGiacomo M. The relationship of trait emotional intelligence with academic performance: a meta-analytic review. Learn Individ Differ. 2013;28:20-33. doi:10.1016/j.lindif.2013.08.002

40. Yahaya A, Bachok NSE, Yahaya N, Boon Y, Hashim S, Goh ML. The impact of emotional intelligence element on academic achievement. Arch Sci. 2012;65(4):2-17.

41. MacCann C, Jiang Y, Brown LE, Double KS, Bucich M, Minbashian A. Emotional intelligence predicts academic performance: a meta-analysis. Psychol Bull. 2020;146(2):150. doi:10.1037/bul0000219

42. Trigueros R, Aguilar-Parra JM, Cangas AJ, Bermejo R, Ferrandiz C, López-Liria R. Influence of emotional intelligence, motivation and resilience on academic performance and the adoption of healthy lifestyle habits among adolescents. Int J Environ Res Public Health. 2019;16(16):2810. doi:10.3390/ijerph16162810

43. Astin AW. Student involvement: a developmental theory for higher education. J Coll Stud Personnel. 1984;25(4):297-308.

44. Reyes MR, Brackett MA, Rivers SE, White M, Salovey P. Classroom emotional climate, student engagement, and academic achievement. J Educ Psychol. 2012;104(3):700. doi:10.1037/a0027268

45. Wolfe MJ. Affective schoolgirl assemblages making school spaces of non/belonging. Emot Space and Soc. 2017;25:63-70. doi:10.1016/j. emospa.2017.05.010

46. Hornung O, Dittes S, Smolnik S, When emotions go social - understanding the role of emotional intelligence in social network use. Research-in-Progress Papers; 2018:40. Available from: https://aisel. aisnet.org/ecis2018_rip/40. Accessed June 16, 2021.

47. Atat FW, Kala K, Jean R. Use and Influence of Social Media on Student Performance in Higher Education Institutions in Cameroon. Emergent Research Forum (ERF); 2018:1-5.

48. Lau WW. Effects of social media usage and social media multitasking on the academic performance of university students. Comput Human Behav. 2017;68:286-291. doi:10.1016/j.chb.2016.11.043

49. Ravizza SM, Hambrick DZ, Fenn KM. Non-academic internet use in the classroom is negatively related to classroom learning regardless of intellectual ability. Comput Educ. 2014;78:109-114. doi:10.1016/j. compedu.2014.05.007

50. Junco R, Heiberger G, Loken E. The effect of Twitter on college student engagement and grades. J Comput Assist Learn. 2011;27 (2):119-132. doi:10.1111/j.1365-2729.2010.00387.x

51. Gregory P, Gregory K, Eddy E. The instructional network: using Facebook to enhance undergraduate mathematics instruction. J Comput Math Sci Teach. 2014;33(1):5-26.

52. van Schaaijk A, Noor Baloch A, Thomée S, Frings-Dresen M, Hagberg M, Nieuwenhuijsen K. Mediating factors for the relationship between stress and work ability over time in young adults. Int J Environ Res Public Health. 2020;17(7):2530. doi:10.3390/ ijerph17072530
53. Rasool SF, Wang M, Zhang Y, Samma M. Sustainable work performance: the roles of workplace violence and occupational stress. Int J Environ Res Public Health. 2020;17(3):912. doi:10.3390/ ijerph 17030912

54. Mehta S, Singh NA. Review paper on emotional intelligence: models and relationship with other constructs. Int J Manag Inf Technol. 2013;4(3):342-353. doi:10.24297/ijmit.v4i3.772

55. Ansari JAN, Khan NA. Exploring the role of social media in collaborative learning: the new domain of learning. Smart Learn Environ. 2020;7(1):1-16. doi:10.1186/s40561-020-00118-7

56. Kauser S, Awan AG. Impact of using social media on academic performance of students at graduate level: evidence from Pakistan. Glob J Manag Soc Sci Humanities. 2019;5(1):116-142.

57. Chand Habiba D, Hussain T, Hassan A. Correlation between autonomous learning and academic performance of university students: a case of Pakistan. PalArchs J Archaeol Egypt. 2021;18(4):2883-2891.

58. Hair JF, Risher JJ, Sarstedt M, Ringle CM. When to use and how to report the results of PLS-SEM. Eur Bus Rev. 2019;31(1):2-24. doi:10.1108/EBR-11-2018-0203

59. Henseler J, Ringle CM, Sarstedt M. A new criterion for assessing discriminant validity in variance-based structural equation modeling. J Acad Mark Sci. 2015;43(1):115-135. doi:10.1007/s11747-0140403-8

60. Rasool SF, Samma M, Wang M, Zhao Y, Zhang Y. How human resource management practices translate into sustainable organizational performance: the mediating role of product, process and knowledge innovation. Psychol Res Behav Manag. 2019;12:1009. doi:10.2147/PRBM.S204662

61. Hair JJF, Hult GTM, Ringle C, Sarstedt M. A Primer on Partial Least Squares Structural Equation Modeling (PLS-SEM). Sage Publications; 2016.

62. Roldán JL, Sánchez-Franco MJ. Variance-based structural equation modeling: guidelines for using partial least squares in information systems research. In: Mora M, Gelman O, Steenkamp A L, Raisinghani M, editors. Research Methodologies, Innovations and Philosophies in Software Systems Engineering and Information Systems. IGI Global; 2012:193-221.

63. Zysberg L, Zisberg A. Days of worry: emotional intelligence and social support mediate worry in the COVID-19 pandemic. $J$ Health Psychol. 2020;1359105320949935. doi:10.1177/1359105320949935

64. Suleman Q, Hussain I, Syed MA, Parveen R, Lodhi IS, Mahmood Z. Association between emotional intelligence and academic success among undergraduates: a cross-sectional study in KUST, Pakistan. PLoS One. 2019;14(7):e0219468. doi:10.1371/journal.pone.0219468

65. NAJAFI, H. Presenting the causal model of the components of blended learning and emotional intelligence and their effect on academic performance. Iran J Med Educ. 2019;19(82):271-281.

66. Mursidi A, Darma Y, Achmad TY, Ting I-H. The effect of social media on the emotional intelligence of teachers in Indonesia. Paper presented at: International Workshop on Learning Technology for Education in Cloud; 2019.

67. Kumari S Role of personality, self-esteem and emotional intelligence on selfie obsession and social media usage; 2019. Available from: http://hdl.handle.net/10266/5498. Accessed June 16, 2021.

68. Bernard KJ, Dzandza PE Effect of social media on academic performance of students in Ghanaian Universities: a case study of University of Ghana, Legon; 2018. Available from: http://ugspace. ug.edu.gh/handle/123456789/31545.

69. Lahiry S, Choudhury S, Chatterjee S, Hazra A. Impact of social media on academic performance and interpersonal relation: a cross-sectional study among students at a tertiary medical center in East India. $J$ Educ Health Promot. 2019;8. doi:10.4103/jehp.jehp_365_18

70. Alnjadat R, Hmaidi MM, Samha TE, Kilani MM, Hasswan AM. Gender variations in social media usage and academic performance among the students of University of Sharjah. J Taibah Univ Med Sci. 2019;14(4):390-394. doi:10.1016/j.jtumed.2019.05.002 
71. Habes M, Alghizzawi M, Khalaf R, Salloum SA, Ghani MA. The relationship between social media and academic performance: Facebook perspective. Int J Inf Technol Lang Stud. 2018;2 (1):12-18.

72. Rouis S, Limayem M, Salehi-Sangari E Impact of Facebook usage on students' academic achievement: role of self-regulation and trust; 2011.
73. Desmal AJ. The impact of using social media and internet on academic performance case study Bahrain Universities. EAI Endorsed Transac Scalable Inf Syst. 2017;4(13).

74. Iqbal J, Qureshi N, Asghar MZ. Psychometric properties analysis of student classroom engagement scale in the academia of Pakistan. PalArchs J Archaeol Egypt. 2021;18(5):355-370.

\section{Publish your work in this journal}

Psychology Research and Behavior Management is an international, peer-reviewed, open access journal focusing on the science of psychology and its application in behavior management to develop improved outcomes in the clinical, educational, sports and business arenas. Specific topics covered in the journal include: Neuroscience, memory and decision making; Behavior modification and management; Clinical applications; Business and sports performance management; Social and developmental studies; Animal studies. The manuscript management system is completely online and includes a very quick and fair peer-review system, which is all easy to use. Visit http://www. dovepress.com/testimonials.php to read real quotes from published authors. 